\title{
EDITORIAL
}

\section{Adolescent Health in Bangladesh}

Adolescents comprise 23 per cent of the total population of Bangladesh, currently numbering 27 million which is likely to increase to 30 million the end of year. About $48 \%$ and $52 \%$ of them are females and males respectively. Adolescence is considered as 'demographically dense' period during the life cycle of the individual, because more demographic actions take place during this period than the rest of the life of the individual. Annual growth rate of adolescent population in Bangladesh is very high at $4.33 \%$, compared to $1.7 \%$ for the total population.

Adolescence is a time for great hope and promise in life. It can be a springboard for producing wellbalanced, educated and responsible citizens or can be time where all potentials may be lost and turn them into social delinquents.

Until recently they have been totally missing from the government health and family planning programmes as they were not considered as sexual entities until they were married. After the age of 5 years when their survival is reasonably assured, they fall off the radar screen of health services; girls showing up when they get complications of pregnancy and boys rarely unless they become victims of accident, violence other social vices.

In Bangladesh, like many other developing countries adolescent girls are at a more disadvantage compared to adolescent boys. Early marriage and childbearing is the custom. Approximately $75 \%$ of the girls are married before the age of 16 years, though the legal age of marriage for females is 18 years. About half of the females aged $15-19$ years are already married compared to only $5 \%$ in males.

In Bangladesh $31 \%$ of the adolescents are already mothers and $5 \%$ are currently pregnant. The adolescent fertility rate in Bangladesh is high with 155 births per thousand, which is one of the highest in the world. Most of the adolescents deliver at home and only $7.4 \%$ of those birth are attended by trained health workers. This coupled with smaller pelvic dimensions because of the incomplete growth of the pelvic bones and consequent smaller size of the pelvis puts the adolescents at a greater risk of obstetric complications. Maternal mortality rate is high in Bangladesh, and the death rate in adolescents is several times more than the average for the country. Because of the societal and family pressure to prove fertility soon after marriage, the contraceptive prevalence rate amongst the adolescents is much lower - only $31 \%$ compared to the national level of more than $60 \%$.

About $50 \%$ of the female adolescents are illiterate, and $45 \%$ has no access to mass media. Malnutrition among adolescents, particularly female adolescents is high. Only 25\% of the female adolescents are employed, and only $50 \%$ of those earn some cash income. Even among those earning cash only two-third have command over their own earnings. No formal sex education is available to the adolescents, and most of their knowledge about sex and sexuality is derived from peers, friends and acquaintances that are often wrong.

The important areas in which attention has to be given in improving adolescent health in Bangladesh include:

Prevention of early marriage ,child-bearing and unwanted pregnancies

Improvement in nutrition

Opportunities for education, particularly for female adolescents

Prevention of STD/RTI

Prevention of addiction, violence and other social evils

Employment and improvement in earning capacity

Since the ICPD Conference in 1994, Government of Bangladesh has recognized that the adolescents are a very important sector of the population which has been under served, and in the Essential Service Package of the Health and Population Sector Strategy (HPSP), many of the needs of the adolescent population has been incorporated.

Free education for female adolescents upto Class VIII is also having a significant impact in improving the rate of female education and there are plans to continue this 
at a higher level of education. Earning opportunities for female adolescents are also increasing and a sizeable number are now employed in the garment sector.

There are currently about 200 non-government organizations, which are working with adolescents. Most are involved in vocational training for skill development, micro credit, leadership training, adolescent family life education, sex education, reproductive heath services, improvement of personal hygiene and other health education and legal assistance in case of violence and abuse against women. Though many of these NGOs are small, there are few, which are spread out all over the country, and have the potential to have significant impact on the health of the adolescents in future.
What has been done is laudable much more needs to be done both at the government and at the societal level to provide adequate health, education, and employment facilities for this vast section of the population with immense possibilities.

(J Banagladesh Coll Phys Surg 2015; 33: 1-2)

\section{Prof. T A Chowdhury}

Professor of Obstetrics \& Gynaecology, BIRDEM \&

Past President, BCPS 